\title{
BMJ Open Assessing the appropriateness of the management of upper respiratory tract infection in Australian children: a population-based sample survey
}

Janet C Long, ${ }^{1}$ Helena M Williams, ${ }^{2}$ Shefali Jani, ${ }^{3}$ Gaston Arnolda, ${ }^{1}$ Hsuen $\mathrm{P}$ Ting, ${ }^{1}$ Charlotte J Molloy, ${ }^{1,4}$ Peter D Hibbert, ${ }^{1,4}$ Kate Churruca, ${ }^{1}$ Louise A Ellis, ${ }^{0} 1$ Jeffrey Braithwaite 1

To cite: Long JC, Williams HM, Jani S, et al. Assessing the appropriateness of the management of upper respiratory tract infection in Australian children: a population-based sample survey. BMJ Open 2019;9:e026915. doi:10.1136/ bmjopen-2018-026915

- Prepublication history and additional material for this paper are available online. To view these files, please visit the journal online (http://dx.doi. org/10.1136/bmjopen-2018026915).

Received 27 September 2018 Revised 10 April 2019 Accepted 11 April 2019
Check for updates

(C) Author(s) (or their employer(s)) 2019. Re-use permitted under CC BY-NC. No commercial re-use. See rights and permissions. Published by BMJ.

For numbered affiliations see end of article.

Correspondence to

Professor Jeffrey Braithwaite; jeffrey.braithwaite@mq.edu.au

\section{ABSTRACT}

Objective To assess the proportion of Australian children aged 0-15 years that received care in line with clinical practice guidelines (CPGs) for upper respiratory tract infections (URTIs).

Design Retrospective medical record review using a multistage sampling strategy.

Setting General practices, hospital emergency departments and hospital inpatient service providers in three Australian states.

Participants Children aged up to 15 years who received care for URTI in 2012 and 2013.

Primary and secondary outcome measures The primary assessment was estimated adherence with 14 indicators of appropriate care as documented in medical records. Indicators were extracted from national and international CPGs and ratified by experts. Secondary assessment was adherence to two bundles of indicators (diagnostic symptoms and medical history taking), where all indicators must be adherent for the bundle to be scored as adherent.

Results There were 1653 children with one or more assessments of URTI care to CPG adherence. Over half of the children were under 3 years of age, with roughly equal numbers of males and females. Three indicators had fewer than 25 visits so were not reported. Overall adherence ranged from $0.5 \%$ for 'documented advice around antibiotics' to $88.3 \%$ for 'documentation of medical history'. Adherence with Bundle A (documentation of all three definitive symptoms) was $43.1 \%$ (95\% Cl $32.8 \%$ to $54.0 \%$ ) and Bundle B (documentation of all four indicators of medical history) was $30.2 \%$ (95\% Cl $20.9 \%$ to $40.9 \%)$.

Conclusions URTIs in children are common, usually self-limiting, conditions that are allocated considerable resources. The results suggest that there may be a need for more thorough holistic assessment of the patient and improved documentation. Since inappropriate prescription of antibiotics for URTIs is still a known problem in Australia, there is a need for consistent, clear communication around antibiotics' lack of impact on symptoms and a high association with undesirable side effects.
Strengths and limitations of this study

- The study used a multistage representative sample across three Australian states, generalisable to the population.

- Using medical records allowed assessment of guideline adherence in real-world settings.

- Lack of documentation of an action was interpreted as indicating the action did not occur.

- Registered paediatric nurses familiar with childhood illnesses and management extracted data from medical records.

- The patient's whole medical record was available to nurses extracting data not just the occasion of care.

\section{INTRODUCTION}

Upper respiratory tract infections (URTIs) are characterised by nasal congestion, rhinorrhoea, cough, sore throat and fever with a median duration of symptoms of $7-15$ days. ${ }^{12}$ It is estimated that a normal child will experience five viral URTIs per year, ${ }^{3}$ but more than $10 \%$ of children have 10 or more 'colds' per year. ${ }^{1}$ It has been suggested that first-time parents may be surprised and concerned by this frequency and misunderstand treatment options. $^{4}$

URTIs are one of the most frequent problems managed by general practitioners (GPs) in Australia. ${ }^{5}$ The Bettering the Evaluation And Care of Health (BEACH) study found that URTI presentations made up $3.3 \%$ of an Australian GP's workload, being third in frequency to hypertension and immunisations/vaccinations. ${ }^{5}$ Children under 15 years old made up $31 \%$ of these patients and $17 \%$ are under 5 years old. ${ }^{6}$ While URTIs are self-limiting, minor ailments, this represents a considerable use of time and resources. Other costs attributed to URTIs in children are mainly due to lost work time for carers. ${ }^{7}$ 
National clinical practice guidelines (CPGs) for assessment and management of childhood URTIs have been developed in a number of countries such as USA, ${ }^{8-10}$ Sweden, ${ }^{11} \mathrm{UK}^{12}$ and Australia. ${ }^{1314}$ Most guidelines around assessment are consensus based as research on the clinical management on URTIs is scarce. ${ }^{5}$ As URTIs are predominantly viral in origin and therefore mostly self-limiting, the clearest guidelines address the appropriate use of antibiotics and assessment for complications such as peritonsillar abscess, bacterial sinusitis or pneumonia, or differential diagnoses such as pertussis. Other guidance addresses issues of care process, such as ensuring history and comorbidities are taken into account (eg, neutropaenia), and general advice to return if symptoms worsen or do not resolve.

Inappropriate management of URTIs in children can lead to overtreatment of a self-limiting condition, unnecessary antibiotic use leading to side effects, resistance of pathogenic bacteria, and increased burden for families. As one of the most frequent childhood illnesses, these considerations are significant. ${ }^{12-14}$

CareTrack Kids (CTK) assessed care of Australian children aged 0-15 years, in 2012 and 2013, to determine the proportion that received care in line with CPGs for 17 common conditions. ${ }^{15}$ Across the 17 conditions, appropriate care per occasion of care was provided at an average of $59.8 \%$ (95\% CI $57.5 \%$ to $62.0 \%$ ), and at $53.2 \%$ $(95 \%$ CI $46.6 \%$ to $59.8 \%)$ for URTI. ${ }^{15}$ We present and discuss the CTK results for URTI at indicator level.

\section{METHODS}

The CTK methods have been reported in detail elsewhere. ${ }^{15-17}$ We describe some aspects specifically relevant to URTI, with a focus on indicator development.

\section{Development of indicators}

The RAND-UCLA method was modifiedcicators. ${ }^{18}$ This study defined a clinical indicator as a measurable component of a standard or guideline, with explicit criteria for inclusion, exclusion, time frame and practice setting. ${ }^{19}$ More details on the development of indicators have been published separately. ${ }^{20}$

Three CPGs were found following a systematic search for Australian and international CPGs for URTI relevant for the years 2012-2013. From these three, 20 recommendations were extracted. Recommendations were screened for eligibility and excluded if they: (1) contained indefinite wording (eg, 'may', 'could'); (2) had a low likelihood of being documented; (3) consisted of guiding statements without recommended actions or (4) addressed aspects of care deemed out of scope of the CTK study such as 'structure-level' recommendations. Thirteen recommendations were excluded, with the remaining seven passed to internal review.

Candidate recommendations were ratified by experts over a two-stage multiround modified Delphi process, which comprised an email-based three-round internal review and a collaborative, online, wiki-based two-round external review, custom designed for the study. ${ }^{17}$ In total, 10 experts (comprising nine paediatricians and one GP) were recruited for the internal $(n=3)$ and external review $(n=7)$. An expert coordinator was appointed to lead the reviews for each condition. Reviewers completed a conflict of interest declaration ${ }^{17}$ and these were managed according to an established protocol. ${ }^{21}$

In the internal review experts scored each recommendation against three criteria (acceptability, feasibility and impact $)^{17}$ and recommended inclusion or exclusion. External reviewers applied the same scoring criteria as internal reviewers and, in addition, used a nine-point Likert scale to score each indicator as representative of appropriate care delivered to children during 2012 and $2013 .{ }^{1718}$ Internal and external reviewers completed their assignments independently to minimise group think. ${ }^{22}$ Four recommendations were ratified by this process and these were formatted into 14 medical record audit indicator questions. All indicator questions are shown in online supplementary appendix 1 .

\section{Sample size, sampling process and data collection}

A minimum of 400 medical record reviews per condition was required to obtain national estimates with $95 \%$ CIs and precision of $\pm 5 \%$, without adjustment for design effects. CTK targeted 400 medical records for URTI and 6000 medical records for 16 other conditions. If any of the 6400 medical records we targeted and sampled contained a visit for URTI, a separate assessment of appropriateness was made for each occasion. Information about the sampling methods have been published; ${ }^{15}$ additional details specific to URTI can be found in online supplementary appendix 2. Briefly, we sampled three healthcare settings (hospital inpatients, emergency department (ED) presentations and consultations with GPs) in health department administrative units (health districts) in Queensland, New South Wales and South Australia, for children aged $\leq 15$ years receiving care in 2012 and 2013. For the broader CTK study, the recruitment rate was $92 \%$ for hospitals and estimated to be $24 \%$ for GPs (see online supplementary appendix 2). Data were collected by nine experienced paediatric nurses trained to assess eligibility for indicator assessment and adherence with CPGs. Medical records for selected visits in 2012 and 2013 were reviewed on-site at each participating facility from March to October 2016. Data collectors had access to the entire medical record, not just the occasion of care.

\section{Analysis}

At indicator level, estimates of adherence were measured as the percentage of eligible indicators (ie, indicators answered either 'yes' or 'no') which were scored as 'yes'. Adherence results for some clinically related indicators were aggregated as bundles of care. For example, indicators URTI01-URTI03 all relate to the documentation of symptoms of children who presented with URTI; all three of these indicators would have to be scored 'yes' for 
the bundle to be scored as adhering to the CPG. When assessing bundles, a visit was only included if there were responses for all component indicators.

Sampling weights were constructed as specified in online supplementary appendix 2 to adjust for oversampling of states and healthcare settings and for sampling within health districts. The weighted data were analysed in SAS V.9.4 (SAS Institute), using the SurveyFreq procedure. Variance was estimated by Taylor series linearisation and the primary sampling unit (health district) was specified as the clustering unit. Stratification and, where appropriate, domain analyses were used (see online supplementary appendix 2). Exact 95\% CIs were generated using the modified Clopper-Pearson method except when the point estimate was $0 \%$ or $100 \%$ where the unmodified Clopper-Pearson method was used. ${ }^{23}$ In both indicator and bundle reports results were suppressed if there were $<25$ eligible visits, as small sample sizes could lead to misleading estimates. Differences in adherence rates between settings were restricted to comparisons between GP and the two hospital settings; as hospitals records were not sampled independently, they were not compared statistically. Statistical significance, where calculated, was based on the F-test approximation of the Rao-Scott $\mathrm{X}^{2}$ test, which adjusts for the design effect.

\section{Ethical considerations}

Australian Human Research Ethics Committees can waive requirements for patient consent for external access to medical records if the study entails minimal risk to healthcare providers and patients; ${ }^{16}$ all relevant bodies provided this waiver. Participants were protected from litigation by gaining statutory immunity for CTK as a quality assurance activity from the Federal Minister for Health under part VC of the Health Insurance Act 1973 (Commonwealth of Australia). Ethical approvals included reporting by healthcare setting for URTI.

\section{Patient and public involvement}

This study did not involve patients or the public.

\section{RESULTS}

There were 1653 children with one or more assessable CPG indicators for URTI, with the age and sex distribution shown in table 1 . Over half of the children in the CTK sample were under 3 years of age, with roughly equal number of males and females. Of 38290 possible indicator assessments, 11831 (30.9\%) were designated as not applicable or otherwise ineligible. The field team conducted 26459 eligible indicator assessments grouped into 2714 visits, at a median of 10 indicators per visit. Eligible URTI visits were assessed in 81 GP practices, 34 hospital EDs and 25 hospital inpatient service providers.

\section{Adherence}

The assessed guideline adherence for each indicator is shown in table 2, presented by healthcare setting and
Table 1 Characteristics of the eligible children with visits for URTI, 2012-2013

\begin{tabular}{lc}
\hline Characteristic & Children in the CTK Study \\
\hline Age $^{\star}-$ no. (\%) & $46(2.8)$ \\
$<3$ months & $262(15.8)$ \\
3-11 months & $568(34.4)$ \\
1-2 years & $363(22.0)$ \\
3-5years & $350(21.2)$ \\
6-12 years & $64(3.9)$ \\
13-15years & $878(53.1)$ \\
\hline
\end{tabular}

*The child's age was calculated as the age at visit where there was only one, or the midpoint of the child's age at her first and last URTI visit, where there was more than one.

CTK, CareTrack Kids; URTI, upper respiratory tract infection.

overall. Adherence is not reported for three of the 14 indicators because they were assessed in fewer than 25 visits and for some settings in the other 11 indicators. For the 11 reported indicators, overall adherence ranged from $0.5 \%$ (95\% CI $0.1 \%$ to $1.5 \%$ ) for indicator URTI09 ('Parents of children with an URTI were advised against antibiotics as they may have side effects') to $88.3 \%$ (95\% CI $79.3 \%$ to $94.4 \%$ ) for URTI05 ('Children who presented with an URTI had their previous medical history documented'). The IQR for overall adherence in the 11 indicators reported was $14.2 \%-70.3 \%$. Large CIs on many of the indicators show substantial uncertainty in the estimates.

By healthcare setting, estimated adherence in ED and inpatient settings was generally higher than in GP settings. As shown in table 2, adherence in the GP setting was statistically significantly lower than in the ED setting for six indicators (URTI01, URTI03-04, URTI06, URTI09, URTI14), and in the inpatient setting for four indicators (URTI01, URTI05-07).

The assessed adherence for two bundles of care is shown in table 3, for all three settings and overall. Bundle A assessed the documentation of three symptoms (runny nose, cough and fever) and found $43.1 \%$ overall adherence (95\% CI $32.8 \%$ to $54.0 \%$ ); the component indicator with the lowest adherence was documentation of the presence of a runny nose $(61.4 \%, 95 \%$ CI $51.4 \%$ to $70.8 \%$; URTI01). Bundle B covered four indicators relating to the documentation of medical history and found $30.2 \%$ adherence (95\% CI $20.9 \%$ to $40.9 \%$ ); the component indicator with the lowest adherence was documentation of comorbidities $(42.2 \%, 95 \%$ CI $32.0 \%$ to $52.8 \%$; URTI04).

\section{DISCUSSION}

This study assessed the guideline adherence of care for URTI provided to children aged $0-15$ years in GP practices, EDs and inpatient services. Overall, guideline 
Table 2 Adherence by clinical indicator and by healthcare setting, 2012-2013

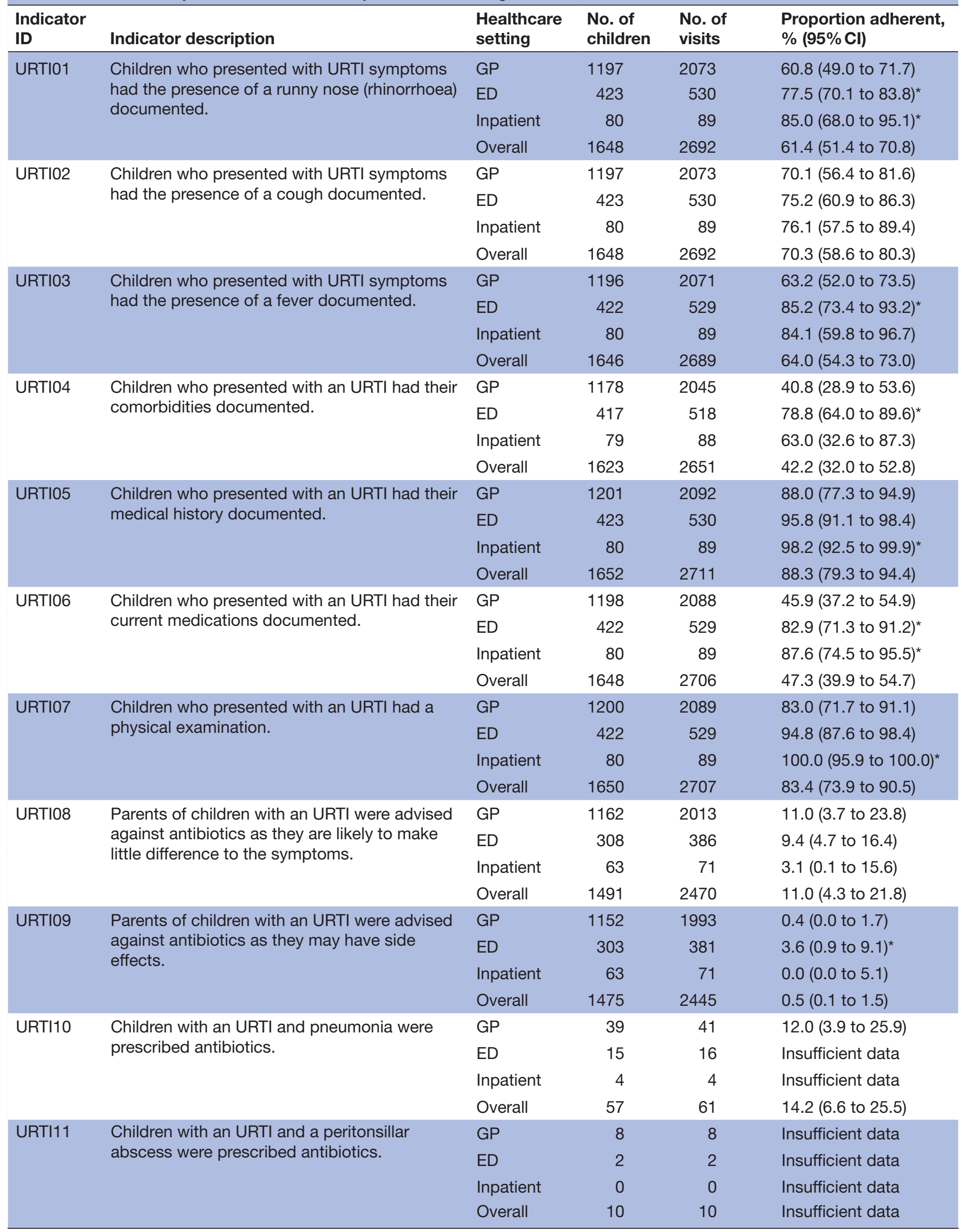


Table 2 Continued

\begin{tabular}{|c|c|c|c|c|c|}
\hline $\begin{array}{l}\text { Indicator } \\
\text { ID }\end{array}$ & Indicator description & $\begin{array}{l}\text { Healthcare } \\
\text { setting }\end{array}$ & $\begin{array}{l}\text { No. of } \\
\text { children }\end{array}$ & $\begin{array}{l}\text { No. of } \\
\text { visits }\end{array}$ & $\begin{array}{l}\text { Proportion adherent, } \\
\%(95 \% \mathrm{Cl})\end{array}$ \\
\hline \multirow[t]{3}{*}{ URTI12 } & \multirow{3}{*}{$\begin{array}{l}\text { Children with an URTI and Bordetella pertussis } \\
\text { were prescribed antibiotics. }\end{array}$} & GP & 9 & 9 & Insufficient data \\
\hline & & Inpatient & 1 & 1 & Insufficient data \\
\hline & & Overall & 15 & 16 & Insufficient data \\
\hline & \multirow{3}{*}{$\begin{array}{l}\text { Children with an URTI and acute moderate/ } \\
\text { severe bacterial sinusitis were prescribed } \\
\text { antibiotics. }\end{array}$} & ED & 1 & 1 & Insufficient data \\
\hline & & Inpatient & 3 & 3 & Insufficient data \\
\hline & & Overall & 21 & 24 & Insufficient data \\
\hline \multirow[t]{2}{*}{ URTI14 } & \multirow{2}{*}{$\begin{array}{l}\text { Parents of children with an URTI were advised } \\
\text { to return if the condition worsens or becomes } \\
\text { prolonged. }\end{array}$} & GP & 1183 & 2054 & 54.8 (46.8 to 62.7$)$ \\
\hline & & ED & 368 & 451 & $78.4(71.1 \text { to } 84.5)^{\star}$ \\
\hline
\end{tabular}

${ }^{*} E D /$ inpatient adherence statistically significantly higher than GP adherence at $p<0.05$.

$\mathrm{ED}$, emergency department; GP, general practitioner; URTI, upper respiratory tract infection.

adherence was found to be suboptimal and inconsistent with indicator scores ranging from $88.3 \%$ (URTI05) to $0.5 \%$ (URTI09).

Documentation of medical history scored the highest of the indicators at $88.3 \%$ (URTI05) but is only one aspect of a holistic assessment required to make appropriate management decisions; that is, to rule out more serious underlying disease (eg, cystic fibrosis) and to limit exacerbation of chronic conditions (eg, asthma). ${ }^{4}$ The second bundle of care measured documentation of medical history, comorbidities, current medications and a physical examination. All four aspects were documented in only $30.2 \%$ of patient encounters, indicating that one or more important aspects of assessment were potentially being overlooked. It could be argued that children who were seeing their usual GP or were regular presenters at the ED (eg, a well-known patient with asthma or cystic fibrosis) may not have had these comorbidities documented at each individual episode of care. However, auditors had access to the whole medical record and were instructed to consider this when determining whether indicators were eligible for scoring (ie, to check for previous entries or summaries likely to have been referred to by clinicians).

Children under 3 months of age were included in the study and accounted for $2.8 \%$ of the cohort. We acknowledge that it is difficult at that age to differentiate URTI from early bronchiolitis.

Antibiotics are not indicated for uncomplicated viral URTI presentations and their inappropriate use may contribute to the major problem of antibiotic resistance, ${ }^{12}$ and put children at risk of side effects. Other studies investigating this issue have measured inappropriate prescribing rates of $20.2 \%$ for children under 5 years of age with uncomplicated URTIs, ${ }^{24}$ and $46 \%$ of patients

Table 3 Adherence by bundle of care and healthcare setting, 2012-2013

\begin{tabular}{|c|c|c|c|c|c|c|c|}
\hline $\begin{array}{l}\text { Bundle } \\
\text { ID }\end{array}$ & Bundle description & $\begin{array}{l}\text { Indicator } \\
\text { IDs* }\end{array}$ & $\begin{array}{l}\text { Healthcare } \\
\text { setting }\end{array}$ & $\begin{array}{l}\text { No. of } \\
\text { children }\end{array}$ & $\begin{array}{l}\text { No. of } \\
\text { visits }\end{array}$ & $\begin{array}{l}\text { No. of } \\
\text { indicator } \\
\text { assessments }\end{array}$ & $\begin{array}{l}\text { Proportion adherent, } \\
\%(95 \% \mathrm{Cl})\end{array}$ \\
\hline \multirow[t]{4}{*}{ A } & \multirow{4}{*}{$\begin{array}{l}\text { Children who presented } \\
\text { with URTI symptoms had } \\
\text { the presence of symptoms } \\
\text { documented. }\end{array}$} & \multirow[t]{4}{*}{ 01-03 } & GP & 1196 & 2071 & 6213 & 42.5 (30.5 to 55.2) \\
\hline & & & ED & 422 & 529 & 1587 & 59.1 (46.5 to 70.9 ) \\
\hline & & & Inpatient & 80 & 89 & 267 & 60.4 (44.1 to 75.2$)$ \\
\hline & & & Overall & 1646 & 2689 & 8067 & 43.1 (32.8 to 54.0 ) \\
\hline \multirow{3}{*}{ B } & \multirow{3}{*}{$\begin{array}{l}\text { Children who presented } \\
\text { with an URTI had medical } \\
\text { history documented. }\end{array}$} & \multirow{3}{*}{$04-07$} & ED & 415 & 516 & 2064 & 68.2 (51.4 to 82.1$)$ \\
\hline & & & Inpatient & 79 & 88 & 352 & 55.6 (29.8 to 79.4$)$ \\
\hline & & & Overall & 1618 & 2643 & 10572 & 30.2 (20.9 to 40.9 ) \\
\hline
\end{tabular}

*In table 2, the indicator ID was preceded by 'URTI'.

ED, emergency department; GP, general practitioner; URTI, upper respiratory tract infection. 
of all ages with URTI in Australian general practice. ${ }^{25}$ Prescribing for non-specific URTI increased fourfold in the UK between 1996 and 2006. ${ }^{26}$ Pressure from parents to receive a prescription for antibiotics is a frequently mentioned issue affecting physicians' prescribing practice (eg, 25 27-29). A study in South East Wales suggested that parents of preschool children were being influenced to inappropriately seek antibiotics by the policy and social pressure exerted by day care providers, contrary to the evidence on URTI treatment. ${ }^{30}$ A Canadian cluster-randomised trial which trained family physicians to engage parents in shared decision-making around treatment options demonstrated that it is possible to reduce the rate of inappropriate antibiotic use in children with acute respiratory infections by $60 \% .^{31}$

Two indicators were included in our study that relate to explaining to parents why antibiotics are not indicated (URTI08-09) to address this social pressure and ensure engagement with, and education of parents. These indicators were guided by the National Institute for Health and Care Excellence 2008 guidelines which recommend: 'When the 'no antibiotic prescribing strategy' is adopted, patients should be offered reassurance that antibiotics are not needed immediately because they are likely to make little difference to symptoms and may have side effects, for example, diarrhoea, vomiting and rash.' Our indicators reflect this advice yet seem infrequently given to parents in our study or were not documented. Indicator URTI09 ('Parents of children with an URTI were advised against antibiotics as they may have side effects') showed the lowest level of adherence across the indicators $(0.5 \%)$ with indicator URTI08 ('Parents of children with an URTI were advised against antibiotics as they are likely to make little difference to the symptoms') scoring second lowest with $11 \%$. There may be several reasons for this: the advice may have been given but not documented; antibiotics may have been (inappropriately) prescribed; or pressure for antibiotic prescription may not have been an issue needing to be addressed. Alternatively, discussions around the inappropriateness of antibiotics to treat an uncomplicated URTI may have been framed in a different way that auditors did not judge as equivalent; for example, focussing instead on the viral nature of URTIs and how antibiotics are only effective against bacterial infections.

Our study did assess circumstances in which antibiotic prescription was appropriate. Appropriateness of antibiotic prescription for children with concurrent pneumonia (URTI10) was only $14.2 \%$ in the aggregated data and on breakdown by setting, only GPs had a large enough number of presentations to report. GPs for this indicator scored $12.0 \%$ (95\% CI $3.9 \%$ to $25.9 \%$ ), which is surprisingly low. The BEACH study ${ }^{24}$ measured antibiotic prescription rates for children under 5 years diagnosed with pneumonia as $65.6 \%$. Given that $85 \%$ of children with URTI and pneumonia in our study were under 5 years of age, it is not clear why our results differ. The BEACH study relies on physician documentation of a special form, while our study examined what was documented in the medical record. As early as 2005 , we have Australian survey evidence of a high level of penetration of electronic medical record use by GPs $(\sim 90 \%)$, with $98 \%$ of users 'mostly' using the inbuilt prescribing tool, so underdocumentation seems unlikely to be the source of the discrepant results, at least for this setting. ${ }^{32}$ It remains possible that the relatively small number of occasions of care surveyed $(n=61)$, has by chance led to an unrepresentative result. Another reason may have been the lack of specificity of URTI10 which did not differentiate between bacterial and viral pneumonia. Insufficient data from EDs and inpatient settings did not allow a comparison.

Strengths of the study include the large sample of Australian children: 1653 children with one or more eligible indicator assessments were analysed. Another strength was the use of paediatric registered nurses who underwent 5 days of training and assessment in auditing the indicators before collecting data, and who were familiar with childhood illnesses and management. This increased the likelihood that records were correctly interpreted, and data recorded accurately. A weakness of the study is the use of documentation to assess actual practice; that is, if it was not documented, it was assumed it did not occur. We note, however, that from a litigation, insurance and auditing point of view, documentation is an accepted proxy measure for action and has been shown to be acceptably correlated with actual practice. $^{33} 34$

Clinically, this study suggests the need for more thorough holistic assessment of the patient including consideration of all four aspects included in the indicators here (comorbidities, medical history, current medications and physical examination). Since inappropriate prescription of antibiotics for URTIs is still known to be a problem in Australia, ${ }^{24}$ there is a need for consistent clear communication and patient education around antibiotics' lack of impact on symptoms and the risks of undesirable side effects.

\section{CONCLUSION}

Uncomplicated URTIs are a common condition of childhood, with considerable time and resources expended in assessing and managing them. ${ }^{5}$ This study has shown that appropriate care may not be delivered consistently and there is room for improvement. Guideline adherence for bundles of care, that require all component indicators to be addressed, was low: documentation of all three common diagnostic symptoms was only adhered to in an estimated $43.1 \%$ of visits, and holistic assessment of the patient using four indicators was only adhered to in $30.2 \%$ of visits. In a context where pressure from parents still drives inappropriate antibiotic use for children with URTI, advice to parents was infrequently reported $(0.5 \%$ and $11 \%)$. 
Author affiliations

${ }^{1}$ Australian Institute of Health Innovation, Macquarie University Faculty of Medicine and Health Sciences, Sydney, New South Wales, Australia

${ }^{2}$ Russell Clinic, Blackwood, South Australia, Australia

${ }^{3}$ Emergency Department, Children's Hospital at Westmead, Westmead, New South Wales, Australia

${ }^{4}$ Division of Health Sciences, School of Health Sciences, University of South Australia, Adelaide, South Australia, Australia

Contributors JB and PDH designed the overall study. SJ and HMW contributed to design of URTI study. JB, PDH, GA, HPT and CJM carried out the collection and statistical analysis of the data. JL drafted the manuscript and was responsible for coordination of all aspects of the work. KC and LAE reviewed and made substantial contributions to earlier drafts. All authors contributed to the interpretation of results and the final manuscript.

Funding This work was supported by an Australian National Health and Medical Research Council Partnership grant (APP1065898), with contributions by the National Health and Medical Research Council, Bupa Health Foundation, Sydney Children's Hospital Network, New South Wales Kids and Families, Children's Health Queensland and the South Australian Department of Health (SA Health).

Competing interests None declared.

Patient consent for publication Not required.

Ethics approval Primary ethics approval was received from hospital networks (HREC/14/SCHN/113; HREC/14/QRCH/91; HREC/14/WCHN/68) and the Royal Australian College of General Practitioners (NREEC 14-008), and site-specific approvals from 34 sites.

Provenance and peer review Not commissioned; externally peer reviewed.

Data sharing statement All additional data are provided in online supplementary appendix.

Open access This is an open access article distributed in accordance with the Creative Commons Attribution Non Commercial (CC BY-NC 4.0) license, which permits others to distribute, remix, adapt, build upon this work non-commercially, and license their derivative works on different terms, provided the original work is properly cited, appropriate credit is given, any changes made indicated, and the use is non-commercial. See: http://creativecommons.org/licenses/by-nc/4.0/.

\section{REFERENCES}

1. Grüber C, Riesberg A, Mansmann U, et al. The effect of hydrotherapy on the incidence of common cold episodes in children: a randomised clinical trial. Eur J Pediatr 2003;162:168-76.

2. Thompson M, Vodicka TA, Blair PS, et al. Duration of symptoms of respiratory tract infections in children: systematic review. BMJ 2013;347:f7027.

3. Chonmaitree T, Revai K, Grady JJ, et al. Viral upper respiratory tract infection and otitis media complication in young children. Clin Infect Dis 2008;46:815-23.

4. Bush A. Recurrent respiratory infections. Pediatr Clin North Am 2009;56:67-100

5. Cooke G, Valenti L, Glasziou P, et al. Common general practice presentations and publication frequency. Aust Fam Physician 2013;42:65-8.

6. The BEACH (Bettering the Evolution And Care of Health) Study. Australian Institute of Health and Welfare General Practitioner Statistics and Classification Centre, 2005.

7. Carabin H, Gyorkos TW, Soto JC, et al. Estimation of direct and indirect costs because of common infections in toddlers attending day care centers. Pediatrics 1999;103:556-64.

8. Dowell S, Marcy S, Phillips W, et al. Principles of judicious use of antimicrobal agents for pediatric upper respiratory tract infections. Pediatrics 1998;101:163-5.

9. Wong DM, Blumberg DA, Lowe LG. Guidelines for the use of antibiotics in acute upper respiratory tract infections. Am Fam Physician 2006;74:956-66.

10. Wald ER, Applegate KE, Bordley C, et al. Clinical practice guideline for the diagnosis and management of acute bacterial sinusitis in children aged 1 to 18 years. Pediatrics 2013;132:e262-e280.
11. Medical Products Agency. Medical treatment of rhinosinusitis (Läkemedelsbehandling av rinosinuit). Sweden (Läkemedelsverket): Information från Läkemedelsverket: Medical Products Agency, 2005:7-48.

12. National Institute for Health and Care Excellence. Respiratory tract infections - antibiotic prescribing: Prescribing of antibiotics for selflimiting respiratory tract infections in adults and children in primary care: NICE, 2008.

13. Patterson CA, Mackson JM, Weekes LM. Antibiotic prescribing for upper respiratory-tract infections in primary care. Commun Dis Intell 2003;27:S39-S41.

14. Respiratory Expert Group. Therapeutic guidelines: respiratory Melbourne. Australia: Therapeutic Guidelines Limited, 2015.

15. Braithwaite J, Hibbert PD, Jaffe A, et al. Quality of Health Care for Children in Australia, 2012-2013. JAMA 2018;319:1113-24.

16. Hooper TD, Hibbert PD, Hannaford NA, et al. Surgical site infection-a population-based study in Australian adults measuring the compliance with and correct timing of appropriate antibiotic prophylaxis. Anaesth Intensive Care 2015;43:461-7.

17. Wiles LK, Hooper TD, Hibbert PD, et al. CareTrack Kids-part 1. Assessing the appropriateness of healthcare delivered to Australian children: study protocol for clinical indicator development. BMJ Open 2015;5:e007748.

18. Fitch K, Bernstein SJ, Aguilar MD, et al. The RAND/UCLA appropriateness method user's manual. Santa Monica, CA: RAND Corp, 2001.

19. Runciman WB, Coiera EW, Day RO, et al. Towards the delivery of appropriate health care in Australia. Med J Aust 2012;197:78-81.

20. Wiles LK, Hooper TD, Hibbert PD, et al. Clinical indicators for common paediatric conditions: Processes, provenance and products of the CareTrack Kids study. PLoS One 2019;14:e0209637.

21. National Health and Medical Research Council. Guideline development and conflicts of interest: Identifying and Managing Conflicts of Interest of Prospective Members and Members of NHMRC Committees and Working Groups Developing Guidelines Canberra NHMRC. 2012.

22. Hasson F, Keeney S. Enhancing rigour in the Delphi technique research. Technol Forecast Soc Change 2011;78:1695-704.

23. Korn E, Graubard B. Confidence intervals for proportions with small expected number of positive counts estimated from survey data. Surv Methodol 1998;24:193-201.

24. Biezen R, Pollack AJ, Harrison C, et al. Respiratory tract infections among children younger than 5 years: current management in Australian general practice. Med J Aust 2015;202:262-5.

25. Dekker AR, Verheij TJ, van der Velden AW. Inappropriate antibiotic prescription for respiratory tract indications: most prominent in adult patients. Fam Pract 2015;32:401-7.

26. Thompson PL, Spyridis N, Sharland M, et al. Changes in clinical indications for community antibiotic prescribing for children in the UK from 1996 to 2006: will the new NICE prescribing guidance on upper respiratory tract infections just be ignored? Arch Dis Child 2009;94:337-40.

27. Bauchner H, Pelton SI, Klein JO. Parents, physicians, and antibiotic use. Pediatrics 1999;103:395-401.

28. Senok AC, Ismaeel AY, Al-Qashar FA, et al. Pattern of upper respiratory tract infections and physicians' antibiotic prescribing practices in Bahrain. Med Princ Pract 2009;18:170-4.

29. Boccazzi A, Noviello S, Tonelli P, et al. The decision-making process in antibacterial treatment of pediatric upper respiratory infections: a national prospective office-based observational study. Int J Infect Dis 2002:6:103-7.

30. Rooshenas L, Wood F, Brookes-Howell L, et al. The influence of children's day care on antibiotic seeking: a mixed methods study. $\mathrm{Br}$ $J$ Gen Pract 2014;64:e302-e312.

31. Légaré $\mathrm{F}$, Labrecque $\mathrm{M}$, Cauchon $\mathrm{M}$, et al. Training family physicians in shared decision-making to reduce the overuse of antibiotics in acute respiratory infections: a cluster randomized trial. CMAJ 2012;184:E726-E734.

32. Mclnnes DK, Saltman DC, Kidd MR. General practitioners' use of computers for prescribing and electronic health records: results from a national survey. Med J Aust 2006;185:88-91.

33. McGlynn EA, Asch SM, Adams J, et al. The quality of health care delivered to adults in the United States. $N$ Engl J Med 2003;348:2635-45.

34. Dresselhaus TR, Luck J, Peabody JW. The ethical problem of false positives: a prospective evaluation of physician reporting in the medical record. J Med Ethics 2002;28:291-4. 